\title{
ALEXIS NIKOLAEVISH LEONTIEV E A TEORIA DA ATIVIDADE
}

\author{
Alexis nikolaevish Leontiev e a theory of activity
}

\author{
Rosana de Fátima Silveira Jammal Padilha - IFPR-UTFPR/ Brasil
} Domingos Leite Lima Filho - UTFPR/Brasil

\begin{abstract}
RESUMO: O presente artigo é um estudo teórico que tem por objetivo apresentar a Teoria da Atividade e seu fundador, o teórico russo Alexis Nikolaevish Leontiev. Através de pesquisa bibliográfica buscou responder as seguintes questões: i) quem foi Leontiev? ii) Em que contexto produziu sua Teoria? E, iii) que elementos de sua teoria podem ser apresentados como relevantes? Neste estudo chegou à seguinte conclusão: que o método que a sustenta (o materialismo-histórico-dialético), o que se permitiu descrever e analisar a constituição da consciência humana, e o conteúdo teórico daí proveniente (um instrumental teórico de descrição e análise) ultrapassa os limites de seu tempo histórico e de suas intencionalidades locais, podendo servir como uma densa teoria de constituição de significações das mais diversas.
\end{abstract}

Palavras-chave: Teoria da Atividade, Leontiev, significação.

ABSTRACT: The present work aims to present the Theory of Activity and its founder, the Russian theorist Alexis Nikolaevish Leontiev. Through bibliographic research he tried to answer the following questions: i) who was Leontiev; ii) in what context produced his Theory; and, iii) what elements of his theory can be presented as relevant. The work came to the following conclusion: that the method that sustains it (materialism-historical-dialectic), what has been allowed to describe and analyze constitution of human consciousness, and theoretical content a theoretical instrument of description and analysis) go beyond the limits of their historical time and local intentions, and can serve as a dense theory of the constitution of significance of the most diverse.

Keywords: Theory of Avtivity, Leontiev, significance.

\section{INTRODUÇÃO}

Segundo Prestes (2012), para conhecer um pensador é necessário conhecer o contexto no qual ele existiu, seu tempo, seu país, seus vínculos de amizade, sua trajetória de vida, sua forma de compreender. Pressupõe-se, assim, não poder ignorar a relação entre esse contexto histórico-social e as produções teóricas daí resultantes. Contudo, a autora também observa que essa tarefa não é fácil, simples ou isenta de riscos. Principalmente, quando aqueles aos quais se deseja conhecer viveram e criaram em épocas de fortes turbulências históricas e sociais. 
Acrescentando-se ao colocado por Prestes (2012), observa-se, aqui, que se aproximar de um teórico com as características de Alexis Nikolaevish Leontiev é tarefa ainda mais difícil, quando se observa a questão da língua e a questão da disponibilidade de seus textos. Entretanto, esses impeditivos não foram suficientes para que se abortasse a empreita, que se propôs neste trabalho: conhecer a Teoria da Atividade e seu principal autor. Para isso, buscou-se apoio em outros estudiosos ${ }^{1}$ que também se aproximaram desse teórico e de sua teoria e realizou-se a leitura dos principais textos de Leontiev, disponíveis em português, espanhol e inglês.

Dessa forma, o que se vai abordar ao longo deste artigo é o resultado desse estudo teórico que teve como principal objetivo conhecer Leontiev e sua Teoria da Atividade. E tentar responder a algumas questões consideradas fundamentais: quem foi Leontiev? Em que contexto produziu sua Teoria? Quais os vínculos de sua produção teórica? A quais objetivos buscou atender? Que elementos apresentou como relevantes? Questões que serão abordadas nos tópicos a seguir.

\section{QUEM FOI ALEXIS NIKOLAEVISH LEONTIEV E EM QUE CONTEXTO PRODUZIU A TEORIA DA ATIVIDADE?}

Alexis Nikolaevish Leontiev (doravante Leontiev) nasceu em 18 de fevereiro de 1903, na cidade de Moscou. E foi considerado um dos mais importantes estudiosos soviéticos a trabalhar com Vigotski e Lúria, com os quais compôs a Troika², equipe que

\footnotetext{
$1 \mathrm{O}$ primeiro contato com a Teoria da Atividade se deu por sugestão de leitura do orientador de Doutorado, quando se buscava pensar um problema de pesquisa surgido na prática profissional da autora deste texto: qual o significado da docência EBTT (Ensino Básico, Técnico e Tecnológico) para aqueles que exercem essa docência? Dessa sugestão, chegou-se ao primeiro texto de Leontiev: Atividade, consciência e personalidade, em uma versão traduzida para o espanhol e publicada em Buenos Aires por Ediciones Ciencias Del Hombre, em 1978. Desse texto, em diante o caminho foi longo, dois anos (entre 2016 e 2018) de muitas outras buscas e leituras, nesse trajeto conheceu-se os escritos de Rhayane Lourenço da Silva, Marta Shuare, Lígia Márcia Martins, Newton Duarte, Zoia Prestes. Além de leitura de textos disponibilizados no site de marxists.org.

2 Sobre a Troika concordamos aqui com SHUARE, 2017; e SILVA, 2013; no que diz respeito a compreensão da existência desta. Sobre os componentes da Troika: Lev Semyonovich Vygotsky sendo o sobrenome também transliterado como Vigotski, Vygotski ou Vygotsky; nasceu em Orsha, 17 de novembro de 1896 - Moscou, 11 de junho de 1934), foi um psicólogo, proponente da Psicologia culturalhistórica. Pensador importante em sua área e época, foi pioneiro no conceito de que o desenvolvimento intelectual das crianças ocorre em função das interações sociais e condições de vida. Vygotsky é o grande fundador da escola soviética de psicologia histórico-cultural.
}

Educação, Psicologia e Interfaces, Volume 3, Número 1, p. 61-76, Janeiro/Abril, 2019.

ISSN: 2594-5343. DOI: https://doi.org/10.37444/issn-2594-5343.v3i1.129 
inaugurou uma nova abordagem teórica na constituição dos estudos em psicologia russa.

Começou suas atividades científicas em 1924 - ao término de seus estudos na área das Ciências Sociais, no Instituto de Psicologia da Universidade Estadual de Moscou (conhecido posteriormente por Instituto de Psicologia geral e Pedagógica de Academia de Ciências Pedagógicas da URSS) - como assistente e em seguida como colaborador científico. Sua primeira obra importante foi "O desenvolvimento da memória" (El desarrollo de la memoria, 1931), produzido na Academia de Educação Comunista N.K. Krupskaia, onde atuou entre 1927 e 1931.

Entre 1931 e 1976, atuou significativamente na produção científica soviética. Segundo Shuare (2017), seria mais fácil enumerar os problemas de Psicologia que Leontiev não investigou que aqueles aos quais realizou uma contribuição essencial. Consolidando-se como fundador de um enfoque específico: "a teoria da atividade", um marco geral de estudo de todos os processos psíquicos em qualquer plano que sejam investigados (desde o plano filogenético ao social).

Segundo, Silva (2013), há uma visão preconceituosa sobre a ciência soviética que "aterroriza" ainda na atualidade representantes da própria esquerda brasileira. Uma desconfiança, que para essa autora é compreensível, mas está pautada em leituras que rebaixam o trabalho desse teórico a uma caricatura do marxismo associada ao stalinismo. Observa que Leontiev se contrapôs a teoria de base da política stalinista, um positivismo cujo objetivo era negar a especificidade das ciências humanas e de sua distinção metodológica com relação às ciências naturais. E alerta que - observar a dicotomia entre subjetividade e objetividade, com base numa oposição entre linguagem e atividade, que caracteriza a obra de Vigotski pela ênfase na linguagem e a obra de Leontiev pela ênfase na atividade - é uma forma de interpretar incompatível com a filosofia marxiana.

\section{EM QUE CONTEXTO SÓCIO-POLÍTICO-TEÓRICO A TEORIA DA ATIVIDADE FOI FORMULADA?}

Alexander Romanovich Luria (Cazá, 16 de julho de 1902 - Moscou, 14 de agosto de 1977) foi um famoso psicólogo soviético especialista em psicologia do desenvolvimento. Foi um dos fundadores de psicologia cultural-histórica onde se inclui o estudo das noções de causalidade e pensamento lógicoconceitual da atividade teórica como função do sistema nervoso central.

Educação, Psicologia e Interfaces, Volume 3, Número 1, p. 61-76, Janeiro/Abril, 2019. 
Segundo Shuare (2017), a teoria psicológica da Atividade foi elaborada na psicologia soviética a partir das elaborações de Vigotski, Rubinstein ${ }^{3}$ e Leontiev. A sua sustentação inicial é dada por Vigotski a partir de sua concepção histórico-cultural de constituição da psique humana, concepção cujo conceito central é o historicismo; e, cujos conceitos chaves são: interiorização (internalização), signo/instrumento e sistema psicológico.

Essa autora observa que Vigotski interpreta o tempo no sentido do materialismo histórico; ou seja, vê o tempo humano como o processo de desenvolvimento da sociedade, que se realiza a partir da atividade produtiva das pessoas. Cuja característica fundamental é o caráter mediatizado pelo instrumento que se interpõe entre o sujeito e o objeto da atividade. E os eventos psíquicos são produzidos e se desenvolvem historicamente. Ou seja, observa que a história do psiquismo humano é a história social de sua constituição.

Sobre a formação histórico-cultural da psique, Prestes (2012, p. 15), observa que uma das melhores definições dadas é a de Leontiev, ao colocar que "as funções naturais, ao longo do desenvolvimento, são substituídas pelas funções culturais, que são o resultado de assimilação dos meios historicamente elaborados para orientar os processos psíquicos".

Rubinstein, segundo Shuare (2017), compreende que o homem e sua psique não somente se manifestam na realidade, mas formam-se na atividade, inicialmente na atividade prática. Observa que a conduta do homem não se reduz a um conjunto de reações, mas de ações, tendo como elementos constitutivos da atividade: a ação, a operação e o ato, relacionados especificamente com a finalidade, o motivo e as condições nas quais a atividade se realiza. Atentando para o fato que a diferença essencial entre ação e reação é que a ação não é um ato dirigido ao estímulo, mas ao objeto.

\footnotetext{
${ }^{3}$ Serguei Leonidovich Rubinstein, nasceu em Odessa no dia 18 de junho de 1889. Filho de judeus pertencentes a alta sociedade russa e de extrema intelectualidade. Principais obras: $\mathrm{O}$ ser a consciência (1957), O pensamento e os caminhos de sua investigação (1958) e O desenvolvimento da psicologia (1959). Também, deixou os manuscritos inacabados de O homem e o mundo, que foram publicados postumamente, em 1970. Serguei Leonidovich Rubinstein, dedicou sua vida a psicologia, a ciência e, principalmente ao desenvolvimento do novo ser humano socialista.
}

Educação, Psicologia e Interfaces, Volume 3, Número 1, p. 61-76, Janeiro/Abril, 2019. 
Ainda segundo a autora aqui abordada, Rubinstein entende a atividade e a consciência como dois aspectos em unidade, cuja formação compõe um todo orgânico. E assim sendo, coloca como objeto de estudo da psicologia as peculiaridades psicológicas da atividade. Ponto sobre o qual Leontiev diverge (SHUARE, 2017), ao ver na relação dialética entre o comportamento e a atividade o objeto de estudo a ser considerado.

\section{EM QUE CONSISTE A TEORIA DA ATIVIDADE PARA LEONTIEV?}

Leontiev $\left(1972^{4}\right)$ observa que a compreensão que se sustenta na ideia da existência de um sujeito e um objeto independentes entre si, e que se baseia no padrão relacional estímulo-resposta (psicologia americana Skinner), é uma abordagem limitada por residir no fato de que, de um lado, há coisas e objetos, e, do outro lado, há um sujeito passivo influenciado por eles. Abordagem que, para o teórico, ignora o elemento significante das relações reais do sujeito com o mundo objetivo: sua atividade.

Entende que a relação entre o sujeito e o mundo é um processo de relações mediado e não pode ser analisado como algo estático ou ainda direto, como se houvesse uma única porta de entrada ou saída entre o cérebro humano e o mundo. E a questão principal está na compreensão que esses processos, são aqueles que realizam uma vida verdadeira da pessoa no mundo objetivo pelo qual ela está cercada, seu ser social em toda sua riqueza e variedade de suas formas.

E vê a relação entre homem-atividade-mundo como uma relação que não se resume ao agir do homem no mundo ou ao agir do mundo no homem. E sim ao processo do viver, vivenciar o/no mundo (o processo da verdadeira vida das pessoas), que para Leontiev (1972) é a relação interativa homem-mundo, na qual a atividade é um processo de inter-tráfico entre polos opostos, sujeito e objeto.

Para o autor aqui tratado, atividade é uma unidade não-aditiva da vida material, corpórea, do sujeito material. Em um sentido estreito, i.e., no plano psicológico, é uma unidade de vida, mediada pela reflexão mental, por uma imagem, cuja função real é orientar o sujeito no mundo objetivo.

\footnotetext{
${ }^{4}$ Tradução disponível em: https://www.marxists.org/portugues/leontiev/1972/mes/atividade.htm em razão de ser acessível via página do marxista.org não há paginação. Acessada em 18/12/2018
}

Educação, Psicologia e Interfaces, Volume 3, Número 1, p. 61-76, Janeiro/Abril, 2019. 
E, a atividade do indivíduo é um sistema que obedece ao sistema de relações da sociedade onde este está inserido. Fora dessa relação a atividade do indivíduo não existe, sendo assim, a atividade de qualquer indivíduo depende de seu lugar na sociedade.

O que entra em conflito com a visão positivista (segundo o autor) que contrapõe indivíduo e sociedade, como se ambos fossem independentes entre si, como se o mundo externo ao homem fosse desconectado deste, e ao qual fosse possível adaptar-se, como algo que se encaixasse em algo. Ou seja, como se a sociedade fosse um ambiente externo ao qual o homem se adaptasse, como os animais adaptam-se à natureza. E como se nesse processo de adaptação, o homem fosse guiado por seu sucesso ou fracasso. Ignorando-se o fato de que é na sociedade que o homem encontra as condições e os motivos objetivos de sua atividade. O que não corresponde dizer que a atividade do indivíduo meramente copia e personifica os relacionamentos da sociedade e sua cultura. Pois existem algumas ligações cruzadas muito complexas que excluem qualquer redução estrita de um ou de outro. (LEONTIEV, 1972). Entender que a sociedade produz a atividade humana, passa pela compreensão da característica básica que constitui a atividade: o fato dela ter um objeto. E, entender isso passa pela compreensão de que ao se tratar do conceito de atividade, trata-se do conceito de objeto da atividade.

Trata-se de compreender que é a atividade externa que destrava o círculo de processos mentais internos, que o abre para o mundo objetivo, que os processos internos do pensamento são produzidos a partir do externo.

Para o autor, não se pode ignorar que a atividade interna é atividade genuína, que retém a estrutura geral da atividade humana, não importa qual forma ela assume. Uma vez que se reconheça a estrutura comum da atividade prática, externa, e atividade mental, interna, pode-se entender a troca de elementos que constantemente ocorre entre elas, pode-se entender que certas ações mentais podem se tornar parte da estrutura da atividade material, prática, e, reciprocamente, operações externo-motoras podem servir para o desempenho da ação mental na estrutura da atividade puramente cognitiva (LEONTIEV, 1972).

De maneira geral, segundo Leontiev, a atividade está intrinsicamente relacionada ao seu objeto, ao que a motiva. O que distingue as atividades, para ele, são os motivos. E não existe atividade sem motivo, posto que uma atividade desmotivada, o é apenas na 
aparência, ou seja, parece ser sem motivo, pois os motivos estão subjetivamente e objetivamente escondidos.

Leontiev (1972) observa que o que compõe as atividades humanas separadas são as ações que as realizam. Ele considera a ação o processo que corresponde à noção do resultado que deve ser atingido, isto é, o processo que obedece a um objetivo consciente. Assim como o conceito de motivo está correlacionado com o conceito de atividade, o conceito de objeto é correlacionado com o de ação.

O objeto da atividade sempre esteve inter-relacionado ao atendimento de necessidades ${ }^{5}$ individuais e coletivas, numa sociedade onde a centralidade da existência está no trabalho coletivo, que ao produzir atende às necessidades de todos os participantes dessa sociedade. Questão que Leontiev (1972) observa se tornar altamente complexa no desenvolvimento das sociedades. Ou seja, os sistemas inter-relacionados desenvolveram-se e nesse processo as relações tornaram-se mais complexas.

Essa complexidade fragmenta a atividade, na perspectiva do indivíduo, mas ainda assim atende às necessidades desse no coletivo. Ou seja, individualmente colabora-se parcialmente com a atividade global de produção de produtos que atendam às necessidades individuais. Mas a produção individual não dá conta sozinha de atender ao suprimento dessas necessidades. Melhor dizendo, essa necessidade é satisfeita não por resultados "intermediários", mas pela partilha do produto da atividade total que cada um recebe, graças aos relacionamentos entre os participantes que surge no processo de trabalho, isto é, as relações sociais (LEONTIEV, 1972).

A divisão social do trabalho, separa funções, e isso implica diretamente na relação com o motivo que gera a atividade e, consequentemente na relação entre a atividade e as ações que a compõe.

O autor observa ainda, que não se pode entender a atividade, o motivo e a ação como co-dependentes, ou diretamente relacionados, apesar de existir relativa dependência. Para Leontiev, a atividade e a ação são genuínas e realidades não coincidentes, pois uma ação pode realizar várias atividades, além de poder passar de uma atividade para outra, o que revela relativa independência. Isso é devido ao fato de que uma dada ação poder ter motivos distintos, e poder realizar atividades

\footnotetext{
5 O homem é um ser de necessidades, para viver precisa ter suas necessidades atendidas. São necessidades humanas: alimentação, moradia, segurança, reprodução... Necessidades para produção e reprodução da vida.
}

Educação, Psicologia e Interfaces, Volume 3, Número 1, p. 61-76, Janeiro/Abril, 2019. 
completamente diferentes. E o mesmo motivo poder gerar vários objetivos e assim várias ações.

Isso tudo num complexo que pode ser compreendido como "o fluxo geral da atividade que forma a vida humana em sua mais alta manifestação", a atividade global, e as unidades de atividade humana que compõe esse complexo, formam o que Leontiev chama de macroestrutura.

E não se pode ignorar que para o autor tal sistema de análise simultânea exclui qualquer possibilidade de bifurcação da realidade que está sendo estudada, desde que lida não como processos diferentes, mas sim com planos diferentes de abstração. Assim, pode ser impossível à primeira vista, por exemplo, julgar se está lidando, em um caso dado, com ação ou com operação ${ }^{6}$. Atividade é um sistema altamente dinâmico, que é caracterizado por transformações ocorrendo constantemente, pode perder o motivo que a evocou, no caso em que se torna uma ação que percebe talvez um relacionamento bastante diferente do mundo, uma atividade diferente. Reciprocamente, ação pode adquirir uma força motivacional independente e se tornar um tipo especial de atividade; e, finalmente, ação pode se transformar em um meio de alcançar um objetivo capaz de realizar ações diferentes (LEONTIEV 1972). Ou seja, entender esse movimento do sistema, as relações entre motivo, ações e atividade, passa pela compreensão da dialética desse sistema, e pelo entendimento não estanque dessa relação, percebendo-se assim as várias possibilidades realizáveis nesse complexo de relações.

Leontiev observa que as imagens da realidade regulam a atividade do homem, e que essas imagens mentais, qualquer coisa no mundo objetivo, se apresenta ao homem como o que motiva sua atividade. E isso deve ser percebido de uma forma ou de outra, entendido, retido e reproduzido pela sua memória. E essa dinâmica também pode ser estendida aos processos da atividade.

O autor explica que a consciência do homem em sua imediaticidade é o retrato do mundo que se desdobra para ele, um retrato no qual ele próprio, suas ações e estados, estão incluídos. Contudo, não se pode pensar que o produto da atividade guarda em si apenas a imagem mental do homem, ou seja, que é a materialização dessa imagem. Para Leontiev, o produto guarda em si o processo de sua produção, a atividade que o

\footnotetext{
${ }^{6}$ Entende-se por operação, na teoria da atividade, um elemento constitutivo da ação, algumas ações para serem executadas precisam ser realizadas por meio de operações.
}

Educação, Psicologia e Interfaces, Volume 3, Número 1, p. 61-76, Janeiro/Abril, 2019. 
produziu. O que torna o movimento sujeito-atividade-objeto circular e aberto, enquanto o sujeito produz o/no objeto o objeto produz o/no sujeito, é uma via em movimento aberto.

Dessa forma, não há como pensar que há em princípio uma imagem pré-definida e que a atividade seja o processar dessa imagem em ações que se concluirão com a materialização da imagem pré-definida. Ou seja, imagem e objeto correlacionam-se, mas não de forma direta, e sim mediatizada no processo da atividade. E essa mediatização se dá pelos sentidos, pela experiência do processo e pelas ideias, que resultam de memória de outras atividades e da linguagem, construção humana e social da realidade. Sendo assim, para o autor, não é possível, em razão desse processo que haja uma consciência individual independente. Ou seja, um ente indivíduo com consciência desvinculada desse sistema.

Há, dessa forma, uma intersecção entre a psicologia e a sociologia, que não pode ser ignorada. Apesar de, ao longo do processo histórico de constituição da consciência, ocorrer o que Leontiev (1972) chama de destruição da coesão original da consciência do trabalho coletivo e aquela de seus membros individuais. Fenômeno que ocorre devido ao alcance da consciência individual, que se limita à esfera das relações individuais, em um contexto de divisão de classes que coloca as pessoas em relações de oposição, e em níveis desiguais de acesso à produção e ao produto social. Concomitantemente a esse fenômeno são desenvolvidas as noções ideológicas e entram no processo pelos quais os indivíduos específicos tornam-se cientes de suas relações reais de vida. Ou seja, a consciência de si e das relações sociais, das compreensões do mundo real, constituem-se destituídas das reais conexões. E no contexto de uma sociedade que produz mercadorias isso vai se dar de forma ainda mais impactante.

E um processo que vai acarretar em impactos na constituição de conhecimentos do mundo, conceitos, modelos conceituais. Pois, o processo de assimilação de significados ocorre, ao longo do desenvolvimento dos indivíduos em relação com o mundo e com o outro, por meio das relações práticas e linguísticas.

Vai ser desse processo, segundo Leontiev, que se vai constituir o que a psicologia empírica denomina como subjetividade, a parcialidade da consciência humana (LEONTIEV,1972).

Dessa forma, a teoria da atividade, pautada no materialismo histórico dialético, compreende que a consciência é um produto social. Assim, ao se perguntar o que é a 
consciência, a resposta possível, a partir dessas reflexões, é que a consciência é "com ciência", porque o sentido da consciência individual pode existir unicamente em presença da consciência social e da linguagem, que é seu substrato real.

E, pautando-se nas teses marxistas sobre a necessidade e sobre a função real da consciência, Leontiev (1978) exclui por inteiro a possibilidade de considerar em psicologia os fenômenos da consciência apenas como epifenômenos que acompanham os processos cerebrais e as atividades que eles realizam. E defende que a tarefa da ciência psicológica consiste em explicar cientificamente o papel ativo da consciência e que isto é possível só em condições de que se modifique de modo radical o enfoque dos problemas e sobretudo, as condições de que se abandone essa ideia antropológica limitada sobre a consciência, que obriga a buscar a explicação da consciência nos processos que se desenvolvem no cérebro do indivíduo a partir das influências dos estímulos que atuam sobre ele.

Pois, entende que a verdadeira explicação da consciência não está nos processos e sim nas condições e modos sociais dessa atividade que cria sua necessidade, ou seja, na atividade laboral, o trabalho, que passa sem cessar da forma de atividade a forma de existência, da forma de movimento a forma de objetivação. Já que os homens agem sobre o mundo e agem socialmente, em comunicação uns com os outros, em diálogo. E também produzem linguagens, que servem para denominar o objeto, os meios e o processo de trabalho. O que dessa forma, faz com que a linguagem seja a forma de existência da consciência.

O desenvolvimento da consciência em cada homem não se repete no processo histórico-social de produção da consciência. O reflexo consciente do mundo não surge como projeção direta no cérebro das representações e conceitos que elaboraram as generalizações precedentes. Sua consciência é também um produto de sua atividade no mundo objetivo. E a consciência não é a manifestação de alguma capacidade mística do cérebro humano, mas é um produto das suas relações no mundo, relações por meio de seu cérebro, de seus órgãos, de seus sentidos, e de seus órgãos de ação.

Daí resulta que o homem só se converte em sujeito de pensamento (capaz de significar o mundo que o cerca e a si nesse mundo) quando domina a linguagem, os conceitos e a lógica, que constituem um reflexo generalizado da experiência da pratica social, incluindo aquelas tarefas que o homem expõe a seus pensamentos são um 
produto das condições sociais de sua existência. Dessa forma, os pensamentos dos homens, assim como sua percepção, são de natureza histórico-social. As representações, os conceitos e ideias que têm alguns homens vão se formando, enriquecendo, e são submetidas a uma seleção não só no curso da prática individual, mas também sobre a base da experiência incomparavelmente, mas ampla, da pratica social que eles assimilam.

A separação do pensamento da atividade transcorre historicamente, em função da divisão do trabalho, a atividade de cada homem depende de seu lugar na sociedade, das condições que lhe tocam a sorte e de como se vão conformando as circunstancias individuais que são únicas. O homem encontra na sociedade não só condições externas que devem acomodar sua atividade, mas também essas mesmas condições sociais contém os motivos e fins de sua atividade, seus procedimentos e meios; em uma palavra, a sociedade produz a atividade dos indivíduos que a formam e nesse processo a significam.

\section{O SIGNIFICADO}

A partir do pressuposto de que a análise sistêmica da atividade humana permite superar a oposição do fisiológico, psicológico e social, Leontiev (1978), ao comentar e analisar a trama sensorial da consciência, seus entremeios e relações, levanta a problematização do significado e consequentemente do sentido pessoal. $\mathrm{O}$ autor observa que as imagens sensoriais são a forma universal do reflexo psíquico, que é gerado pela atividade objetiva do sujeito. E entende que no homem, as imagens sensoriais adquirem uma nova qualidade, que para ele é justamente seu caráter significativo. Apresentando como ponto a se considerar que os significados são formadores primordiais da consciência humana. Ou seja, observa que não há uma significação à priori na consciência, mas que são os significados que formam a consciência. Assim, a forma ideal de existência do mundo objetivo, de suas propriedades, vínculos e relações, descobertos pela pratica social conjunta está representada no significado- transformada e comprimida na matéria da linguagem. Por isso, dizer que há os significados por si mesmos, é o mesmo que dizer, que abstraídos de seu funcionamento na consciência individual são tão não-psicológicos como a realidade socialmente conhecida que está por trás deles. 
Condições distintas de relações com o outro e com mundo, implicam em dualidade significativas, e isso implica que haja um significado objetivo compreensivo (o entendido por "todos", o social) e um significado para o sujeito (sentido pessoal). Porque os significados são refratados pelas particularidades concretas dos indivíduos, por seu lugar na sociedade, pela divisão social do trabalho, por suas experiências prévias, pela particularidade de suas atitudes, temperamento, etc.

\section{O SENTIDO PESSOAL}

Em Leontiev (1978), falar em sentido pessoal está relacionado ao que se compreende por subjetividade; ou seja, está relacionado à parcialidade da consciência humana. Contudo, para o autor, as dificuldades residem em explicar do ângulo psicológico a parcialidade da consciência. Pois, os fenômenos da consciência parecem ter, para a psicologia empírica, uma dupla determinação, externa e interna, tratada como pertencente a duas esferas da psique humana: a esfera dos processos cognitivos e a esfera das necessidades e afetividade, elementos vistos como independentes.

O autor observa que a verdadeira natureza dessa aparente dualidade dos fenômenos da consciência individual não reside em sua subordinação a esses fatos independentes. Mas, os significados, os sentidos pessoais são o mesmo que a trama sensorial da consciência, não possuem uma existência supraindividual, não psicológica. E estão ligados a constituição dessa subjetividade, dessa parcialidade da consciência humana.

Não se deve ignorar, dessa forma, que o alcance da consciência individual se limita à esfera das relações individuais, em um contexto de divisão de classes, que coloca as pessoas em relações de oposição, e em níveis desiguais de acesso à produção e ao produto social. Concomitantemente a esse fenômeno são desenvolvidas as noções ideológicas e entram no processo pelos quais os indivíduos específicos tornam-se cientes de suas relações reais de vida. Ou seja, a consciência de si e das relações sociais, das compreensões do mundo real, constituem-se destituídas das reais conexões. E o sentido pessoal está relacionado a esse processo.

\section{A TEORIA DA ATIVIDADE E O DESENVOLVIMENTO PESSOAL}

Educação, Psicologia e Interfaces, Volume 3, Número 1, p. 61-76, Janeiro/Abril, 2019.

ISSN: 2594-5343. DOI: https://doi.org/10.37444/issn-2594-5343.v3i1.129 
Leontiev (2001), ao tratar do desenvolvimento psicológico individual, onde o problema teórico das forças motivadoras do desenvolvimento da psique, ou seja a pergunta "o que motiva o desenvolvimento" é discutida, observa que durante o processo de vida, sob as influências das circunstâncias onde ela se realiza, o lugar que ela objetivamente ocupa no sistema de relações humanas se altera. E os modos de vida mudam radicalmente, nos sistema de relações familiar, escolar, laboral. Quando as relações vitais básicas são reestruturadas (marcas de mudança), seu caráter psíquico geral se modifica e todo o sistema de relações é reorganizado. Isso se dá em razão das mudanças de funções e papel social, nesse sistema de relações.

A transição para um novo estágio no desenvolvimento da vida e da consciência ocorre seguindo um mesmo padrão interior. Ao ocupar um novo lugar, a vida adquire novo conteúdo, e isto significa compreender o mundo de uma forma nova. Esse desenvolvimento depende das condições reais de vida do indivíduo. Ao analisar o desenvolvimento do indivíduo, como ele é constituído, nas condições concretas de vida. A vida, ou a atividade como um todo, não é constituída mecanicamente a partir de tipos separados de atividade. Alguns tipos de atividade são os principais em um certo estágio. Algumas representam o papel principal no desenvolvimento, e outras, um papel secundário. Há, dessa forma, uma dependência do desenvolvimento psíquico em relação à atividade principal e não à atividade geral. $\mathrm{O}$ critério de transição de um estágio para o outro é precisamente a mudança do tipo principal de atividade, na relação dominante do indivíduo com sua realidade.

O indivíduo começa a se dar conta, nesse processo, no decorrer do seu desenvolvimento, de que o lugar que costumava ocupar no mundo das relações humanas que o circunda não corresponde às suas potencialidades e se esforça para modifica-lo. Ocorre, dessa forma, uma contradição entre o modo de vida e suas potencialidades, que já superaram esse modo de viver. Ou seja, o tempo passa, o conhecimento aumenta, as capacidades tornam-se maiores, os poderes crescem, as condições de autodirigir-se se modificam e os indivíduos mudam.

Ao abordar como ocorre a mudança da atividade principal, Leontiev (2001) observa que há uma alteração de motivos, na alteração de uma ação que passa a atividade. Há motivos compreensíveis e motivos eficazes, em certas ocasiões há a transição de uns para outros, novos motivos surgem e por conseguinte, um novo tipo de atividade. É uma questão de o resultado de uma ação ser mais significativo em certas 
condições, que o motivo que realmente o induziu. Dependendo de qual atividade a ação faz parte, a ação terá outro caráter psicológico, a depender de qual sentido pessoal tem um fenômeno para o indivíduo.

Sobre a dinâmica geral do desenvolvimento da vida psíquica, Leontiev (2001) destaca que as mudanças observadas nos processos de vida psíquica, dentro dos limites de cada momento, não decorrem de forma independente, mas relacionados entre si. E funções psicológicas como memória, atenção, percepção dependem de seus lugares na atividade, e nela interferem. O que dita o sentido (a direção) do desenvolvimento são mudanças nos círculos de relações vitais e no círculo de sua atividade para o desenvolvimento de ações, operações e funções psíquicas. O indivíduo não se limita, na realidade, a mudar de lugar no sistema das relações sociais. Ele se torna consciente dessas relações e as interpreta. O desenvolvimento de sua consciência encontra expressão em uma mudança na motivação de sua atividade; velhos motivos perdem sua força estimuladora e nascem os novos, conduzindo a uma reinterpretação das ações anteriores. E a atividade que costumava desempenhar o papel principal começa a se desprender e passar para um segundo plano. Uma nova atividade principal surge e com ela começa um novo ciclo de desenvolvimento. É como se a cada marca vivenciada, o indivíduo ressignificasse a própria trajetória e reordenasse o caminho, como se a partir de um GPS (global positioning system- sistema de posicionamento global) próprio (constituído em suas experimentações de vida) o indivíduo recalculasse a própria rota.

\section{CONCLUSÕES}

A Teoria da Atividade é um arcabouço teórico que foi desenvolvido em um determinado tempo histórico, com um objetivo distinto e foi resultado de intensos estudos em um dado contexto histórico-social, em que se buscava produzir material teórico que permitisse a produção de uma nova pedagogia e uma nova psicologia para um novo homem e uma nova educação.

Ao colocar a questão do homem como sujeito de sua história, ao mostrar a constituição do seu ser/existir, de forma que se compreenda que o processo dessa constituição não se realiza de forma dicotômica, descontruindo uma visão autônoma do ser, mas possibilitando perceber a constituição de uma autonomia relativa ao desenvolvimento de uma auto direção de si, a partir da auto compreensão de si, ou seja,

Educação, Psicologia e Interfaces, Volume 3, Número 1, p. 61-76, Janeiro/Abril, 2019. 
possibilitando perceber que a consciência não é algo dado a priori e nem é algo estanque, mas é resultado de um processo que possibilita trânsito e desenvolvimento (e compreendendo que esse desenvolvimento não se faz de forma linear e pode ocorrer inclusive em contextos alienantes). O produzido por Leontiev contribui muito com análises que visem compreender como esse processo se realiza em situações sócio históricas diversas.

Sendo assim, a teoria da atividade permite pensar nos significados sociais e sentidos pessoais que determinados objetos conquistam ao longo de seu processo sócio histórico de constituição para os sujeitos; e com isso, fornece um aparato teórico para realizar à crítica a essa constituição e em grande medida compreender essa constituição.

\section{REFERÊNCIAS BIBLIOGRÁFICAS}

LEONTIEV, A. N. Sobre o desenvolvimento criativo de Vigotski. Tradução do inglês: Marcelo José de Souza e Silva. 28p. Disponível em: <http://www.marxists.org/>. Publicado em 1989 como prefácio ao volume 3 das Obras Escolhidas de Vigotski, em inglês.

LEONTIEV, A. N. El hombre y la cultura. In: LEONTIEV, A. N.; KOSÍK, K.; LURIA, A. El hombre nuevo. Barcelona: Martínez Roca, S. A. Barcelona, 1969. Cap. 3.

LEONTIEV, A. N. El lenguaje y la razón humana. Tradução do russo por: Augusto Vidal Roget. 28p. Montevideo: Ediciones Pueblos Unidos S. A., s/d.

LEONTIEV, A. N. Atividade e Consciência. Tradução do inglês: Marcelo José de Souza e Silva. 20p. Disponível em: <http://www.marxists.org/>. Publicado em russo na revista Voprosy filosofii, n. 12, p. 129-140 (1972) e em inglês no livro Filosofia na URSS: Problemas do Materialismo-Dialético (Moscou, 1977, p. 180-202).

LEONTIEV, A. N. Actividad, conciencia y personalidad. Buenos Aires: Ediciones Ciencias del Hombre, 1978.

MARTINS, L. M. Análise sócio-histórica do processo de personalização de professores. Tese de Doutorado.Programa de Pós-graduação em Educação, Faculdade de Filosofia e Ciências, UNESP. Marília, 2001.

MARTINS, L. M. (2006). As aparências enganam: divergências entre o materialismo histórico dialético e as abordagens qualitativas de pesquisa. Trabalho apresentado na 29a Reunião Anual da ANPED. Disponível em: de http://www.anped.org.br/reunioes/29ra/trabalhos/trabalho/GT17-2042--Int.pdf Acesso em: 20 de setembro de 2011.

MARTINS, L.M. (2012). O desenvolvimento do psiquismo e a educação escolar:contribuições à luz da psicologia histórico cultural e da pedagogia 
histórico-crítica. Tese de Livre-docência em Psicologia, Departamento de Psicologia da Faculdade de Ciências da Universidade Estadual Paulista, campus de Bauru.

PRESTES, Z. R. Quando não é quase a mesma coisa: traduções de Lev

Semionovitch Vigotski no Brasil. Campinas: Autores Associados: 2012.

SHUARE, M. A psicologia soviética meu olhar. São Paulo. Editora Terracota, 2017.

\section{Credenciais da/os autora/es}

PADILHA, Rosana de Fátima Silveira Jammal. Doutora em Tecnologia pela UTFPR e Mestra em Educação pela UFPR, Docente do IFPR- Câmpus Paranaguá/Brasil. E-mail: rosanapadilha10@gmail.com

LIMA FILHO, Domingos Leite. Doutorado em Educação na Universidade Federal de Santa Catarina e Pós-Doutorado na Facultad de Ciencias Sociales da Universidade de Salamanca. É professor do Programa de Pós-Graduação em Tecnologia e Sociedade, área de concentração tecnologia e sociedade da Universidade Tecnológica Federal do Paraná /Brasil. E-mail: domingos@utfpr.edu.br

Endereço para correspondência: Rosana de Fátima Silveira Jammal Padilha, Rua Francisco Arcega, n.416, Bairro Cohapar CEP 83280.000, Guaratuba/PR. E-mail: rosanapadilha10@gmail.com

Como citar este artigo (Formato ABNT): PADILHA, Rosana de Fátima Silveira Jammal; LIMA FILHO, Domingos Leite. Alexis Nikolaevish Leontiev e a Teoria da Atividade. Educação, Psicologia e Interfaces, v. 3, n.1, p.61-76, 2019. DOI: https://doi.org/10.37444/issn-2594-5343.v3i1.129

Recebido: 06/12/2018.

Aceito: 20/03/2019.

Educação, Psicologia e Interfaces, Volume 3, Número 1, p. 61-76, Janeiro/Abril, 2019.

ISSN: 2594-5343. DOI: https://doi.org/10.37444/issn-2594-5343.v3i1.129 